\title{
Research on the Relationship between Enterprise Network Resources and Market Scope of Cross-Regional Integration: An Empirical Study under Condition of Market Segmentation in China
}

\author{
Guangyu Ye, Tiantian Jin, Yan Zhou \\ School of Business Administration, South China University of Technology, Guangzhou, China \\ Email: bmgyye@scut.edu.cn, jtt31415@163.com
}

Received 1 September 2015; accepted 13 October 2015; published 16 October 2015

Copyright (C) 2015 by authors and Scientific Research Publishing Inc.

This work is licensed under the Creative Commons Attribution International License (CC BY). http://creativecommons.org/licenses/by/4.0/

(c) (i) 0 pen Access

\begin{abstract}
In order to survive in the fierce competition in Chinese market, Chinese companies gradually start to integrate the domestic market cross-regionally. Although the integration strategy has already become one of the important growth tactics, there are very few researches focused on enterprise network resources when discussed cross-regional integration, not to mention the special market environment in China-market segmentation. According to resource-based view and social network theory, we studied the relationship between enterprise network resources and the market scope of cross-regional integration. Taking Chinese market segmentation into consideration, we analyzed the moderating effect of institutional distance and entrepreneurial orientation. Based on empirical analysis of $\mathbf{4 3 9}$ valid questionnaires, we found that enterprise network resources had a positive effect on the market scope of cross-regional integration; and institutional distance moderated the correlation between network resources and market scope positively.
\end{abstract}

\section{Keywords}

Enterprise Network Resources, Cross-Regional Integration, Market Scope, Institutional Distance, Entrepreneurial Orientation

\section{Introduction}

As a result of China’s reform and opening-up policy and economic globalization, an increasing number of mul-

How to cite this paper: Ye, G.Y., Jin, T.T. and Zhou, Y. (2015) Research on the Relationship between Enterprise Network Resources and Market Scope of Cross-Regional Integration: An Empirical Study under Condition of Market Segmentation in China. Open Journal of Business and Management, 3, 403-411. http://dx.doi.org/10.4236/ojbm.2015.34039 
tinational companies streamed into China, which drove Chinese enterprises to realize the importance of crossregional integration. As a common business strategy, integration strategy here only refers to horizontal integration strategy, which means that enterprises integrate other companies in other regions. However, for many Chinese companies, it is not easy to integrate the domestic market, and sometimes the emerging obstacles in China market seem more difficult than in international market [1]. On one hand, Chinese domestic market is enormous, and local market segmentation makes institutional differences between regions more remarkable; on the other hand, plenty of large multinational companies gather together in China, which leads to more intense competition [2]. How to implement cross-regional integration smoothly under such circumstances becomes a general difficult problem that most companies faced. Existing researchers discovered that determinant factors of companies' cross-regional integration were rooted in enterprises themselves, but resources owned by companies were numerous and complex; in fact, only transferable resources could promote cross-regional integration [3], such as enterprise network resources. At the same time, the success of cross-regional integration strategy cannot ignore the impact of institutional differences between regions and entrepreneurial orientation. Nevertheless, previous literature rarely mentioned the influence of enterprise network resources on the market scope of cross-regional integration [4], let alone the impact of institutional distance and entrepreneurial orientation. Therefore, under the condition of market segmentation in China, combining resource-based perspective and social network theory, we discussed the relationship between enterprise network resources and the market scope of cross-regional integration (which means how many regions or provinces company have integrated), and analyzed following two factors’ moderating effect: institutional distance and entrepreneurial orientation.

\section{Theoretical Basis and Research Hypothesis}

\subsection{Enterprise Network Resource and the Market Scope of Cross-Regional Integration}

The accumulation of key resources in a company can result in a more advantageous position in the intense competition. Scholars in strategy management believe that resources are not only exited in enterprise internally, but also exited in the interactive networks between firms themselves and other organizations [5]. Generally speaking, enterprise network resource refers to knowledge, information, experience etc. gained from the social relationship which established by interacting with other companies and organizations [6].

Early researches found out that before entering into other nations, multinational companies would often set up relationship networks with local enterprises consciously, as they think it could be helpful to overcome obstacles generated from cultural differences. Some studies admitted the significant effect of network resource and regarded them as the core elements for multinational companies to operate successfully in other regions [7]. In the same way, integrating cross-regionally in huge Chinese market also needs to take enterprise network resources into account. On one hand, with the increase of network resources a firm owned, the company can get more information quickly and seize more market opportunities precisely, and then enter into more regions. On the other hand, cross-regional integration is not just behaving as a kind of operating actions in other regions, but a complex transfer process of managerial philosophy and experience. The obtaining of enterprise network resources actually means establishing a sharing platform which companies in network can share their knowledge and experience on, what is more important, it can reduce the uncertainty of cross-regional integration. Furthermore, as network resources are radioactive, when establish cooperative relation with one firm, it is equivalent to build positive relationship with all the company's partners, which can certainly accelerate the pace of integrating different regions. Therefore, the quantity of network resource an enterprise owned will surely influence the market scope a company can integrate, the richer the network resource, the wider the market scope that company can integrate. Based on the analysis above, we put forward the following hypothesis.

H1: Enterprise network resource is positively related to the market scope of cross-regional integration.

\subsection{The Moderating Effect of Institutional Distance}

Internationalization theory holds the opinion that corporate transnational operation must be affected by institutional environment both in home country and host country, and the extent of the institutional differences between them can influence enterprises' strategic behavior [8]. Kostova defined "institutional distance" as extent of the institutional differences existing between different nations in 1996 [9]. Recently, when mention to "institutional distance”, some scholars don't lay their emphases on institutional distance at the international level, 
while start to apply "institutional distance” within one nation [10], as there actually exist institutional differences between regions or provinces in some countries, for example, China.

As a result of decentralization reform in China, institutional environment between different regions show a lot of differences [11]. The existence of institutional distance between regions surely increase the uncertainty of companies' operation cross-regionally, furthermore, it can lead to the raise of transaction cost and management cost, which makes the cross-regional integration more difficult. And as institutional distance increase, the management system and tradition of parent company are difficult to be applied to corporations in other regions, companies need to devote more time to get used to local institutions. While enterprise network resource can help companies to gain information, experiences that are highly needed in operating outside fast and effectively and thus drive enterprises to integrate wider market scope. Similarly, the smaller the institutional distance, the less the institutional differences between regions entering into and original region, companies can realize successful integration without excessive network resources, as they can copy and modify original business mode. Therefore, the positive effect of enterprise network resource on market scope of cross-regional integration is more significant under the circumstance of bigger institutional distance. Based on the analysis above, we put forward the following hypothesis.

H2: Institutional distance moderates the positive relationship between enterprise network resource and the market scope of cross-regional integration in such a way that the relationship will be stronger when institutional distance is bigger rather than smaller.

\subsection{The Moderating Effect of Entrepreneurial Orientation}

Entrepreneurial orientation reveals company's decisive thinking mode and overall mental outlook, it also represents company's attitude of how to use its own resources. Covin and Slevin (1989) firstly proposed the definition of "entrepreneurial orientation", and explained it as corporate courage of taking risks and company's tendency of innovation consciousness, advanced cognitive [12]. To identify and develop market opportunities is the key point in entrepreneurship theory, while it also needs the support of enterprise network resources. Furthermore, entrepreneurial orientation has a great effect on access and utilization of these resources.

As entrepreneurial orientation of a firm improve, company's desire for expanding to wider market is more intense, and enterprises tend to find more market opportunities based on network resources. Some studies have discovered that companies with high entrepreneurial orientation often have higher resource utilization efficiency [13]; they would like to set up more extensive relationship network based on obvious network resource and integrate wider market further. While as entrepreneurial orientation decline, the desire for expanding decrease, in this case, companies are not willing to take risks and beginning to get used to existing market scope. Even if they possess rich network resources, companies may not seize the market opportunity initiatively; the positive effect of network resources on the market scope of cross-regional integration would weaken sharply. Based on the analysis above, we put forward the following hypothesis.

H3: Entrepreneurial orientation moderates the positive relationship between enterprise network resource and the market scope of cross-regional integration in such a way that the relationship will be stronger when entrepreneurial orientation is higher rather than lower.

\section{Research Design}

\subsection{Variable Measurement}

Market scope of cross-regional Integration: we regard "cross-regional integration" in this research as companies have entered into regions where the headquarters were not located in and have already showed business behaviors there. Thus, we chose two indexes to measure "market scope of cross-regional integration": firstly, the numbers of provinces or autonomous regions that company products or services have entered into; secondly, we took company's investment behavior into consideration, which means, we also measure the numbers of provinces or autonomous regions that company have invested into. All these provinces or autonomous regions above exclude the province or autonomous region where the headquarters were located in.

Enterprise network resources: include knowledge, information, practice organization process and so on acquired from the social relationship with other companies and organizations. As we didn't find a suitable existing measurement scale, so we developed a new scale to measure the variable. According to the defini- 
tion, as the cooperative relationship with other companies gets closed, company will gain more network resources. Hence, we used the Richter magnitude 7 scales and divided network resources into 3 items: include the relationship with suppliers, channel and government to judge the network resources a firm possessed.

Institutional distance: it reflects the extent of institutional environment difference between different regions. To ensure reliability and validity of the result, we imitated Fan Gang's research method by using "marketization index" to represent institutions, thus got the numerical institutional distance by calculating the difference of marketization index between regions. In a word, institutional distance is defined in the following way:

$$
\mathrm{DIS}=\left(\sum_{1}^{n}\left|m a r_{h}-\operatorname{mar}_{i}\right|\right) / n
$$

where DIS is the institutional distance, $\mathrm{mar}_{h}$ stands for the marketization index of where the corporate headquarters are located in, mar $_{i}$ reflects the marketization index of regions where the corporate branches are located in. All the marketization index of provinces in China are collected and calculated based on Fan Gang's annual report, and the results are showed in Table 1 below.

Entrepreneurial orientation: it is defined as company's behavior guide in entering into new regions; it shows the extent of company's innovation, risk-taking and forward thinking. We used the entrepreneurial orientation measurement scale developed by Zhaohui Yi [15] to judge the entrepreneurial orientation of companies be tested.

We also chose the time since companies established and corporate ownership as the control variables.

\subsection{Data Collection}

In order to verify the relations between above variables, we firstly set two standards to choose suitable research objects: at first, companies should have implemented cross-regional integration strategy and showed integration behavior in Chinese market; secondly, each firm's branch offices should be located at regions whose marketization degree is different with the area where headquarters are located. Then we distributed 550 research questionnaires mainly in Guangdong, Zhejiang, Henan provinces, and later withdrawn 517 questionnaires. After eliminating 81 questionnaires that are incomplete or show obvious tendency, finally we got 436 valid questionnaires. Among those were investigated, $43.7 \%$ are middle managers, $38.12 \%$ are senior managers, the rest are managers at basic level; as for the corporate industry, $54.67 \%$ are industry, $34.4 \%$ are service industry, which reflects the current industry development situation in China.

\subsection{Reliability and Validity Test}

SPSS version 21 was used to analyze the data for constructing the relationships and associations between the dependent and independent variables proposed in this research. We chose "Cronbach's alpha" to verify the reliability of the data. The results showed that the Cronbach's alpha of enterprise network resources was 0.93 , the Cronbach's alpha of entrepreneurial orientation' was 0.794, which means the Questionnaire design has high

Table 1. The marketization index of all the provinces in China.

\begin{tabular}{|c|c|c|c|c|c|c|c|c|}
\hline Regions & Zhejiang & Jiangsu & Shanghai & Guangdong & Beijing & Tianjin & Fujian & Shandong \\
\hline MI & 11.8 & 11.54 & 10.96 & 10.42 & 9.87 & 9.43 & 9.02 & 8.93 \\
\hline Regions & Liaoning & Chongqing & Henan & Jiangxi & Hubei & Sichuan & Hunan & Hebei \\
\hline MI & 8.76 & 8.14 & 8.04 & 7.65 & 7.65 & 7.56 & 7.39 & 7.27 \\
\hline Regions & Jilin & Hainan & Neimenggu & Guangxi & Shanxi & Heilongjiang & Yunnan & Ningxia \\
\hline MI & 7.09 & 6.4 & 6.27 & 6.17 & 6.11 & 6.11 & 6.06 & 5.94 \\
\hline Regions & Guizhou & Shanxi’ & Xinjiang & Gansu & Qinghai & Xizang & & \\
\hline MI & 5.56 & 5.65 & 5.12 & 4.98 & 3.25 & 0.38 & & \\
\hline
\end{tabular}

Data source: NERI INDEX of Marketization of China’s Provinces 2011 Report [14]. 
internal consistency reliability. As for validity test, firstly, we calculated the individual KMO values obtained for "enterprise network resources" and "entrepreneurial orientation", the results were all above 0.5 , which indicates a good sampling adequacy for the research data. Then, we used the factor analysis method to test the correlation of each with each factor. Communalities ranging from 0.784 to 0.970 indicate that, none of the observed variables were out of prediction from the two factors extracted. Given all these results, we can draw the conclusion that the Questionnaire design has high reliability and validity.

\section{Results}

In order to testify the relationship between enterprise network resources and the market scope of cross-regional integration, we adopted the method of correlation analysis and multiple regression analysis; also, we chose cross regression analysis method to test the moderating effect of institutional distance and entrepreneurial orientation.

\subsection{Descriptive Statistic Analysis}

Table 2 below reveals mean value, standard deviation, Pearson correlation coefficient of the samples. The mean value of the market scope of cross-regional integration was 3.32, which indicates that at least half of the investigated companies have expanded into 7 - 10 provinces; the standard deviation was 1.928, which reflects that the actual results of integration strategy in different companies have big differences.

\subsection{Regression Analysis}

According to analysis above, we established model 1 to test the correlation of enterprise network resources and the market scope of cross-regional integration:

Model 1:

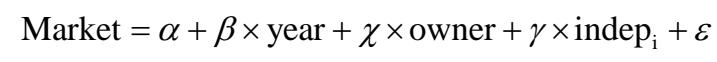

And we established model 2 to test the moderating effect of correlation of institutional distance and entrepreneurial orientation:

Model 2:

$$
\text { Market }=\alpha+\beta \times \text { year }+\chi \times \text { owner }+\gamma \times \text { indep }_{\mathrm{i}}+\phi \times \text { moder }_{\mathrm{j}}+\theta \times \text { indep }_{\mathrm{i}} \times \text { moder }_{\mathrm{j}}+\varepsilon
$$

Among the models above, "Market" reflects the market scope companies integrated cross-regionally, which means how many provinces or regions that company have expanded into; "year" stands for how many years since the company established, "owner" shows the ownership of companies. Besides, "indep" means dependent variables, while "moder" stands for moderate variables mentioned above, such as institutional distance and entrepreneurial orientation. The results are as following Table 3.

1) Hypothesis 1

We can see the regression results from model 1 , when enterprise network resources was dependent variable, the regression coefficient was 0.279 with the significance level reached 0.001 , which tested the positive correlation of enterprise network resource and the market scope of cross-regional integration, H1 was proved.

\begin{tabular}{|c|c|c|c|c|c|c|c|c|}
\hline Variables & M & $\mathrm{SD}$ & 1 & 2 & 3 & 4 & 5 & 6 \\
\hline 1. ENR & 5.1 & 1.1 & 1 & & & & & \\
\hline 2. MSCI & 3.32 & 1.928 & $0.12^{* *}$ & 1 & & & & \\
\hline 3. ID & 1.46 & 1.283 & 0.19 & $0.167^{* *}$ & 1 & & & \\
\hline 4. EO & 4.19 & 1.055 & $0.148^{* *}$ & $0.108^{* *}$ & 0.012 & 1 & & \\
\hline 5. Year & 2.23 & 0.857 & $0.168^{* *}$ & -0.002 & 0.068 & $0.158^{* *}$ & 1 & \\
\hline 6. Own & 2.65 & 0.97 & 0.053 & 0.047 & 0.03 & 0.046 & $-0.319^{* *}$ & 1 \\
\hline
\end{tabular}

Table 2. The marketization index of all the provinces in China. 
Table 3. The results of regression analysis

\begin{tabular}{|c|c|c|c|c|c|c|}
\hline \multirow{3}{*}{$\begin{array}{c}\text { Indep } \\
\text { C }\end{array}$} & \multicolumn{2}{|c|}{ Model 1} & \multicolumn{2}{|c|}{ Model 2 (ID mod) } & \multicolumn{2}{|c|}{ Model 2 (EI mod) } \\
\hline & \multicolumn{2}{|c|}{ MSCI } & \multicolumn{2}{|c|}{ MSCI } & \multicolumn{2}{|c|}{ MSCI } \\
\hline & $0.827(0.223)$ & $0.544(0.298)$ & $0.271(0.48)$ & $2.653^{* * *}(0.000)$ & $1.653(0.576)$ & $-0.026(0.967)$ \\
\hline Year & $0.19(0.330)$ & $0.663^{* * *}(0.000)$ & $0.096(0.324)$ & $0.116(0.236)$ & $0.088(0.367)$ & $0.657^{* * *}(0.000)$ \\
\hline Own & $0.191(0.214)$ & $-0.037(0.695)$ & $0.098(0.205)$ & $-0.107(0.174)$ & $0.092(0.233)$ & $0.037(0.696)$ \\
\hline ENR & & $0.279^{* * *}(0.001)$ & & $0.316^{* * *}(0.000)$ & & 0.04 (0.789) \\
\hline ID & & & $0.096(0.441)$ & $0.05(0.373)$ & & \\
\hline ID $*$ ENR & & & & $0.145^{* * *}(0.000)$ & & \\
\hline $\mathrm{EO}$ & & & & & $0.143^{* *}(0.045)$ & $0.303^{*}(0.057)$ \\
\hline EO*ENR & & & & & & $0.01(0.857)$ \\
\hline $\mathrm{R}^{2}$ & 0.409 & 0.125 & 0.41 & 0.401 & 0.416 & 0.133 \\
\hline $\mathrm{F}$ & 100.278 & 20.745 & 60.182 & 57.998 & 61.712 & 13.238 \\
\hline Sig. F & 0 & 0.000 & 0 & 0 & 0 & 0 \\
\hline
\end{tabular}

\section{2) Hypothesis 2}

As the regression results from model 2 shows, when enterprise network resources behaved as dependent variable, the interaction coefficient between enterprise network resource and institutional distance was 0.145 with the significance level reached $0.000<0.01$, which reflects the moderating effect of institutional distance on the correlation between enterprise network resource and market scope of cross-regional integration. And as the interaction coefficient was $0.145>0$, thus it proved our prediction of the positive regulation effect. $\mathrm{H} 2$ was tested.

3) Hypothesis 3

We can see the regression results from model 2, the interaction coefficient between enterprise network resource and entrepreneurial orientation was 0.01 , but didn't reach the significance level. No sufficient evidence proved the moderating effect of entrepreneurial orientation on the correlation between enterprise network resource and market scope of cross-regional integration. H3 was not proved, which may be caused by the reason that the risk-taking dimension is only a small proportion of all the three dimensions of entrepreneurial orientation; however, it is exactly the critical factor to influence the correlation between enterprise network resource and the market scope of cross-regional integration.

\section{Conclusions}

In conclusion, on one hand, the research results above verify that enterprise network resources have a significant influence on company growth strategy, especially for the cross-regional integration strategy [16]; on the other hand, this paper takes the special institutional environment in China—market segmentation into account, and reminds other participants of Chinese business to keep the domestic institutions in mind for a better development.

What is more, this paper is aimed at providing some suggestions for those companies attempting to enhance competitiveness by integrating more market at other regions. Firstly, corporate should recognize the complicacy of the institutional environment in different regions in Chinese market; secondly, companies should strengthen the cooperative relations with other organizations so as to build a strong support for future development.

\section{Supported}

This paper is supported by The Fund Project of Central University Basic Scientific Research (20BPY09): Internationalization Strategy of Private Corporations-a Perspective of Home Country Constraints. 


\section{References}

[1] Boisot, M. and Meyer, M.W. (2008) Which Way through the Open Door? Reflections on the Internationalization of Chinese Firms. Management and Organization Review, 4, 349-365. http://dx.doi.org/10.1111/j.1740-8784.2008.00116.x

[2] Wang, Y.J. (2014) Enterprises Capabilities, Managerial Cognition and Geographic Diversification: An Empirical Study under Condition of Market Segmentation in China. Ph.D. Thesis, South China University of Technology, Guangzhou.

[3] Lin, J.H. (2008) The Exploration and Analysis of Multinational Company Theory Development Tendency—Research of Combination of New-New Trade Theory and Resource-Based Theory. Economic Issues in China, 6, 3-10.

[4] Peng, M.W. and Delios, A. (2006) What Determines the Scope of the Firm over Time and around the World? An Asia Pacific Perspective. Asia Pacific Journal of Management, 4, 385-405.

[5] Fang, G. and Hu, B.L. (2010) The Classification and Functional Mechanism of Network Resources—Research Based on Knowledge Transfer Perspective. Studies in Science of Science, 10, 1511-1520.

[6] Fan, L.B. (2004) A Framework of the Influence of Network Relations between Corporations on Strategy. Economics of Finance and Trade, 5, 42-46.

[7] Wang, G.S. and Zheng, Z. (2008) The Basic Problem of Enterprise Internationalization Research: A Evolution Theory Perspective. Journal of Central South University: The Social Sciences, 1, 1-4.

[8] Busenitz, W., Gomez, C. and Spencer, W. (2008) Country Institutional Profiles: Unlocking Entrepreneurial Phenomena. The Academy of Management Journal, 5, 994-1003.

[9] Kostova, T. (1998) The Quality of Inter-Unit Relationships in MNEs as a Source of Competitive Advantage. New Managerial Mindsets: Organizational Transformation and Strategy Implementation, 299-324.

[10] Phillips, N., Tracy, P. and Karra, N. (2009) Rethinking Institutional Distance: Strengthening the Tie between New Institutional Theory and International Management. Strategic Organization, 3, 330-348. http://dx.doi.org/10.1177/1476127009337439

[11] Fan, G., Wang, X.L. and Zhu, H.P. (2010) NERI INDEX of Marketization of China's Provinces 2009. Economic Science Press, Beijing.

[12] Covin, J.G. and Slevin, D.P. (1989) Strategic Management of Small Firms in Hostile and Benign Environments. Strategic Management Journal, 10, 75-87. http://dx.doi.org/10.1002/smj.4250100107

[13] Cai, L., Zhu, X.M. and Liu, Y. (2011) Research of the Effect of Entrepreneurial Orientation on Resources Access. Studies in Science of Science, 4, 601-609.

[14] Fan, G., Wang, X.L. and Zhu, H.P. (2011) NERI INDEX of Marketization of China's Provinces 2011. Economic Science Press, Beijing.

[15] Yi, C.H. (2010) Relationship Study of Resource Integration Competence, Entrepreneurial Orientation and Entrepreneurial Performance. Studies in Science of Science, 5, 757-762.

[16] Song, T.B., Tu, P.X. and Wu, X.J. (2013) Resource Capability, Industry Characteristics and Diversification Strategy of Superior Enterprises under the Circumstance of Market Segmentation. Soft Science, 5, 26-31. 


\section{Appendix}

\section{Research Questionnaires}

This research work is undertaking to have an insight on the effect of cross-regional integration strategy of Chinese companies. All information you provide will be treated ad confidential and anonymous, and also will be used for academic research only. Thank you.

\section{General Questions}

1. How long has your company founded?

$\begin{array}{lllll}\text { A. less than } 10 \text { years } & \text { B. } 11-20 \text { years } & \text { C. } 21 \text { - } 50 \text { years } & \text { D. more than } 50 \text { years }\end{array}$

2. The ownership property of your company

$\begin{array}{llll}\text { A. state-owned enterprise } & \text { B. private enterprise } & \text { C. joint venture } & \text { D. foreign-invested enterprises }\end{array}$

3. What industry does your company belong to?

$\begin{array}{llll}\text { A. manufacturing industry } & \text { B. service industry } & \text { C. others }\end{array}$

4. How many employees does your company have?

$\begin{array}{llll}\text { A. less than } 100 & \text { B. } 101-200 & \text { C. } 201-500 & \text { D. more than } 500\end{array}$

5 . How many provinces or regions have your products/services sold into, besides where your headquarter was located in?
A. 1 - 3
B. 4 - 6
C. 7 - 10
D. 11 - 15
E. 16 - $20 \quad$ F. More than 21

6. How many provinces or regions have your company invested into, besides where your headquarter was located in?
A. 1 - 3
B. 4 - 6
C. 7 - 10
D. 11 - 15
E. 16 - 20
F. More than 21

7. Which provinces does your headquarter located in?

(1) Zhejiang (2) Jiangsu (3) Shanghai (4) Guangdong (5) Beijing (6) Tianjin (7) Fujian

(8) Shandong (9) Liaoning (10) Chongqing (11) Henan (12) Jiangxi (13) Hubei (14) Hebei

(15) Sichuan (16) Hunan (17) Heilongjiang (18) Hainan (19) Neimenggu (20) Guangxi

(21) Jilin (22) Shanxi (23) Yunnan (24) Ningxia (25) Guizhou (26) Shanxi’ (27) Guizhou

(28) Xinjiang (29) Gansu (30) Qinghai (31) Xizang

8. Which provinces do your branches located in?

(1) Zhejiang (2) Jiangsu (3) Shanghai (4) Guangdong (5) Beijing (6) Tianjin (7) Fujian

(8) Shandong (9) Liaoning (10) Chongqing (11) Henan (12) Jiangxi (13) Hubei (14) Hebei

(15) Sichuan (16) Hunan (17) Heilongjiang (18) Hainan (19) Neimenggu (20) Guangxi

(21) Jilin (22) Shanxi (23) Yunnan (24) Ningxia (25) Guizhou (26) Shanxi’ (27) Guizhou

(28) Xinjiang (29) Gansu (30) Qinghai (31) Xizang

\section{Other questions}

Please tick the most appropriate that describe your company.

1. Totally disagree; 2. Basically Disagree; 3. Disagree a little; 4. Neither agree nor disagree; 5 . Agree a little; 6. Basically agree; 7 . Totally agree.

\section{Items}

\section{Enterprise network resources}

1. My company has a long cooperative relationship with major suppliers

2. Our major suppliers are reliable

3. Our major suppliers never do anything harmful to us

4. My company has a long cooperative relationship with major dealers

5. Our major dealers are reliable

6. Our major dealers never do anything harmful to us

7. My company has a long cooperative relationship with local government

8. My company enjoy privileges and support from government in profit-oriented land

9. My company enjoyed privileges and support from government in business loans 


\section{Continued}

10. My company enjoy privileges and support from government in taxes

11. My company enjoy privileges and support from government in business activities

\section{Entrepreneurial orientation}

12. My company pay most attention to R \& D and innovation

13. Our new products (services) always update many times

14. Our new products (services) always have brilliant progress than before

15. Our innovations are difficult to imitate for competitors

16. Our business decisions are bold and rapid under uncertain environment

17. Our tolerance for economic damage is high under uncertain environment

18. My company likes programs that are high-risking and high-earnings

19. My company likes to behave boldly and rapidly to achieve goals

20. My company pays close attention to customer demand and market trend

21. My company always introduces and develops new produces (services) rapidly than competitors

22. My company always introduces advancing management theory and methods

23. My company always analyses strategic environment in time 